A C T A C H E I CA SCA N D N A V I A 14 (1960)650-656

\title{
The Activation of Phosphoprotein Phosphatase with Inorganic Phosphate and Surfactants
}

\author{
BO NOR B ER G \\ Chemical central laboratory, Sabbatsbergs sjukhus, Stockholm, Sweden
}

\begin{abstract}
In the determination of the activity of phosphoprotein phosphatase as released inorganic phosphate, $\mathrm{Pi}$, which can be precipitated with calcium at $\mathrm{pH} 9$, the enzyme activity is dependent upon the concentration of $\mathrm{Pi}$, so that the apparent activity approaches 0 in connection with falling $\mathrm{Pi}$, attains a maximum at about $0.1 \mathrm{mM} \mathrm{Pi}$, when the substrate is $1 \%$ phosvitin, and sinks in connection with an even moderate excess of Pi. The enzyme activity is further increased by quaternary ammonium bases such as cetyltrimethylammonium bromide and other detergents. The activation is presumed to be connected with an increased tendency to reaction in the carbinol-group of the serine residue in the substrate.
\end{abstract}

Tn an earlier investigation ${ }^{1}$ it was found that precipitation of the inorganic 1 phosphate (Pi) released by the phosphoprotein phosphatase was necessary in order to get satisfactory reproducibility and proportionality between enzyme concentration and reaction rate. In the course of subsequent work, however, a number of apparently inexplicable irregularities were observed. Thus on one day fresh liver extract gave good activity with two casein substrates (2.17 and 3.86 units per gram liver), whereas much smaller values were obtained the next day (0 and 1.17 units per gram). Experiments with phosvitin ${ }^{2}$ also gave unexpected results, adrenal extract giving higher activity, in 5 out of 6 experiments, than liver extract, as compared with the reverse relation when casein was used as substrate ${ }^{1}$. Parallel measurements of activity were then carried out with casein and phosvitin as substrate, and extract of adrenal glands, erythrocytes and liver from the rat, guinea-pig, rabbit, and cat as enzyme source. With liver in these experiments a higher apparent activity was obtained with casein substrate in 11 out of 13 tests. Adrenals and blood corpuscles, on the other hand, gave higher activity with phosvitin in 10 out of 15 experiments. Since inhibition of phosphoprotein phosphatase with $\mathrm{Pi}$ has been shown ${ }^{1,3}$, and since liver is richer in Pi than are red corpuscles, the irregularities might possibly be due to the occurrence of Pi. Attempts to eliminate the excess Pi by dialysis, however, resulted regularly in a loss of activity. A more careful investigation of the effect of $\mathrm{Pi}$ was therefore indicated. 
In the subsequent experiments human erythrocytes were chiefly used as source of enzyme. In a preliminary series with rat liver, an extract in $0.1 \mathrm{M}$ acetate, of $\mathrm{pH} \mathrm{5.8,} \mathrm{gave} \mathrm{activities} \mathrm{of} \mathrm{between} 3.26$ and 4.76 units per gram, on an average 4.07 with a standard deviation of 0.056 , while an aqueous extract gave 3.88-4.87 units per gram, averaging 4.35. Systematic testing with erythrocyte extract showed optimal activity at an ionic strength of 0.04 . Accordingly the erythrocytes, after 3 washings with isotonic sodium chloride were hemolyzed with distilled water, after which the hemolysate was diluted to $50 \mathrm{mg}$ hemoglobin per $\mathrm{ml}$ and ionic strength 0.2 , using sodium chloride and acetate buffer, $\mathrm{pH}$ 5.8. Phosvitin with about $1.1 \mathrm{mg}$ protein nitrogen per $\mathrm{ml}$ (determined on trichloroacetic acid precipitate) was used as substrate.

Measurement of the enzyme activity was performed by incubating $1 \mathrm{ml}$ extract and $4 \mathrm{ml}$ substrate at $38^{\circ} \mathrm{C}$, then stopping the enzyme effect with trichloroacetic acid and measuring the $\mathrm{Pi}$ released after precipitation with calcium at $\mathrm{pH} \mathbf{9 1}^{\mathbf{1}}$. Apart from this standard method two alternatives were tried: a) direct determination of Pi in the trichloroacetic acid extract according to Fiske-Subbarow and b) extraction of directly obtained phosphomolybdate complex « However, these alternative methods regularly gave lower values than did the standard method, especially at the optimal initial concentration of $\mathrm{Pi}$. In 84 comparisons the standard technique gave on an average $1.61 \pm 0.27$ (standard deviation) times greater activity than did alternative a). The apparent difference in activity is referable to the higher blank value in the alternative methods. The preliminary explanation of this might bo the occurrence of an acid-labile phosphorus linkage in the substrate. In subsequent testing only the standard technique was used.

The revovery of $P i$ which had been added to dialysed substrate was investigated at four phosvitin concentrations. It was found that in order to get a certain blank value more $\mathrm{Pi}$ was required the higher the phosvitin-content. This emerges clearly from Fig. 1, where increasing addition of phosphate does not give a rising blank value until after the addition of $100 \mu$ mole $/ 1$ with approx. $1 \%$ phosvitin, and of $200 \mu$ mole $/ 1$ for $2 \%$ phosvitin.

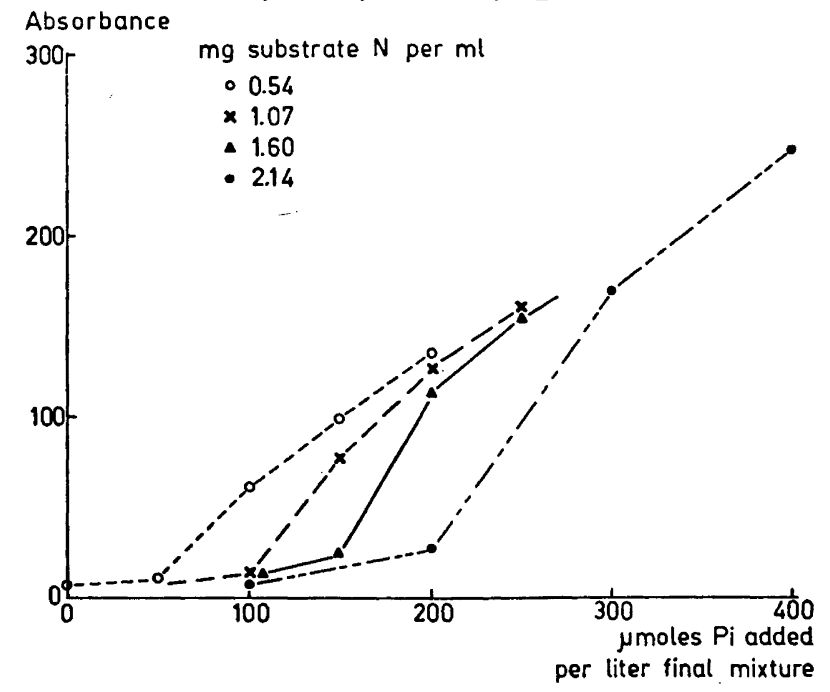

Fig. 1. Apparent inorganic phosphate ( $\mathrm{Pi}$, as absorbance) against total concentration of added $\mathrm{Pi}$ at increasing phosvitin concentrations.

Acta Chem. Scand. 14 (1960) No. 3 


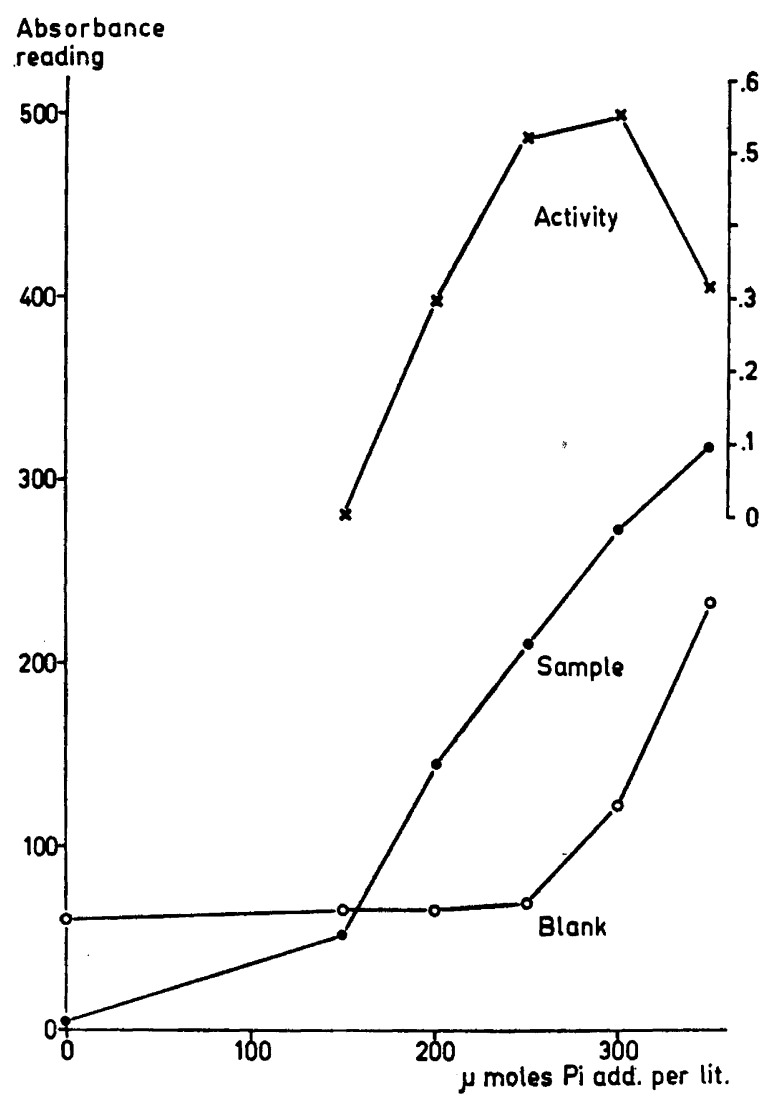

Fig. 2. Effect of addition of inorganic phosphate on blank reading and enzyme activity.

The relation between enzyme activity and added $P i$ is illustrated by the experiment shown in Fig. 2. On the addition of Pi corresponding to up to $0.15 \mathrm{mM}$ no enzyme activity at all is obtained on incubation. On larger additions it increases however, reaching a maximum at the same time as the blank value begins to rise in response to a $\mathrm{Pi}$-addition corresponding to a final concentration of $0.25 \mathrm{mM}$ phosphate at $1.8 \%$ phosvitin. Even slightly larger amounts of $\mathrm{Pi}$ result in inhibition.

In subsequent experiments $1 \%$ phosvitin was usually used as substrate, and maximal enzyme activity was then obtained at a blank value of about $100 \mu \mathrm{M}$ Pi. This appears from a series of experiments comprising 39 tests and reproduced in Fig. 3. When the actual concentration of $\mathrm{Pi}$ found in the blank value exceeds $150 \mu \mathrm{M}$, the activity is greatly reduced. If the initial Pi-value approaches 0 , the enzyme activity disappears entirely. One must obviously determine the content of $\mathrm{Pi}$ in every enzyme sample and adapt the addition of $\mathrm{Pi}$ to the substrate so that the optimal concentration of Pi for the actual substrate is approximately reached; the interval between too little and too much is evidently very small. 


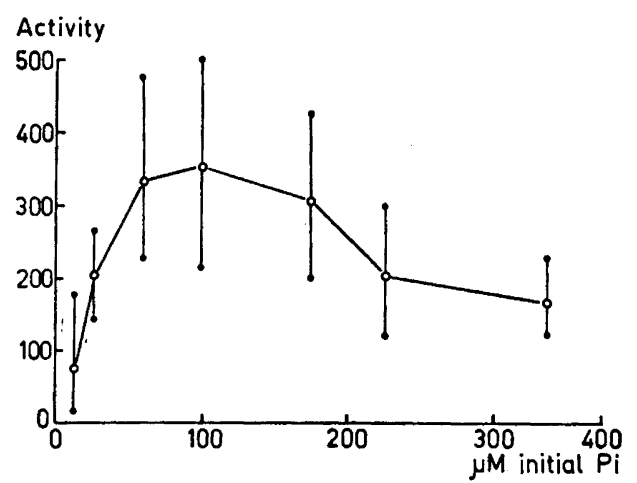

Fig. 3. Actual initial concentration of $\mathrm{Pi}$ at incubation and its effect on enzyme activity (mean value and range). Each mean represents 2 to 8 experiments.

Just how sensitive the enzyme reaction is to excess phosphate is shown in Fig. 4. With a rising incubation period an increasing concentration of $\mathrm{Pi}$ is obtained, which results in increasing inhibition; so that the apparent activity per $100 \mathrm{mg}$ hemoglobin has fallen below $50 \%$ of the highest value measured when the concentration of $\mathrm{Pi}$ has risen to no more than $0.4 \mathrm{mM}$. This striking sensitivity to phosphate in the incubation milieu shows clearly how difficult it is with in vitro experiments to throw light upon the activity of the enzyme in vivo.

In connection with the testing of casein as substrate, quaternary ammonium bases were also added in the dialysis, with the intention of preventing bacterial contamination of the substrate. This resulted, in the majority of the experiments in a not inconsiderable increase in the activity, as is exemplified in Table 1.

Similar results were also obtained with octylphenoxyethoxyethyldimethylbenzylammonium chloride ("Septin" Pharmacia, Uppsala) and cetyltrimethylammonium bromide, CTB, and also with ethylendiamine-tetraacetate, EDTA. The sensitivity of the enzyme to the phosphate ion concentration was not investigated however, and with the exception of some of these tests no attention was paid to this factor. The significance of the addition of phosphate for casein which had been dialyzed against $0.5 \% \mathrm{CPBr}$ with extract from fresh rat's liver as enzyme is shown in Table 2. In other casein substrates which had been dialyzed with or without addition of quaternary ammonium base an addition of phosphate corresponding to $0.12-1.05 \mathrm{mM}$ Pi was required at the start of the incubation, with an average of $0.51 \mathrm{mM}$ Pi for optimal effect (22 substrates with $20 \mathrm{mM}$ organically bound phosphorus).

For testing with phosvitin CTB in a concentration of $10 \mathrm{mM}$ was generally used. The effect of the detergent and of the addition of phosphate is shown in Table 3, which clearly indicates stimulation but also the dependence on the addition of phosphate both without and with CTB. To throw further light upon this, Table 4 shows the results of an experiment in which the phosvitin solutions were prepared directly in water and in $0.01 \mathrm{M}$ CTB, respectively, without dialysis. Here the water substrate gives an apparently very low

Acta Chem. Scand. 14 (1960) No. 3 


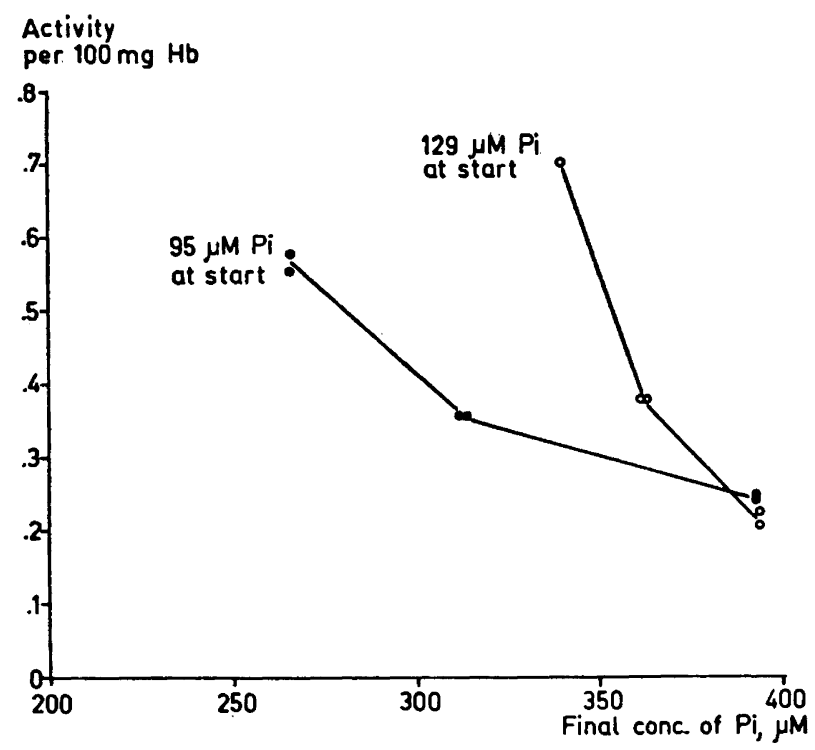

Fig. 4. Increasing inhibition of enzyme activity with rising concentration of Pi in digest. Initial concentration of $\mathrm{Pi} 95 \mu \mathrm{M}$ (dots) and $129 \mu \mathrm{M}$ (circles).

concentration of $\mathrm{Pi}$. In the CTB-substrate, on the other hand, one obtains with increasing phosvitin-concentration a considerable $\mathrm{Pi}$ concentration. The optimal activity is obtained at an apparent concentration of $61 \mu \mathrm{M} P i$ in the substrate $+214 \mu \mathrm{M}$ in the hemolysate. The activation, which apparently derives from the detergent, seems to be intimately connected with the Pi which is available, and at a higher substrate-concentration it turns into a faint but distinct inhibition. The interesting thing about this experiment is that the detergent appears to mobilize the labile phosphorus in the substrate, as there was no special addition of phosphate.

The results of the investigation appear to show that a certain minimal concentration of inorganic phosphorus is required to obtain the greatest possible activity with phosphoprotein phosphatase in the measuring system used. On the other hand, further inorganic phosphorus which is produced by the

Table 1. Phosphoprotein phosphatase activity of rat liver homogenate using casein dialyzed against acetate buffer with or without cetylpyridinium bromide, CPBr.

\begin{tabular}{|c|c|c|c|c|}
\hline \multirow{2}{*}{$\begin{array}{c}\text { Casein } \\
\text { No. }\end{array}$} & \multicolumn{2}{|c|}{ CPBr concentration at dialysis, mM } & $\begin{array}{c}\text { Maximum } \\
\text { change, } \%\end{array}$ \\
\cline { 2 - 5 } & None & $0.26-1.3$ & $2.6-13$ & -20 \\
13 & 0.74 & 0.59 & 0.61 & +29 \\
14 & 1.70 & 2.06 & 2.19 & +825 \\
19 & 0.52 & 3.94 & 4.82 & $+\infty$ \\
21 & 0 & 1.20 & 1.01 & 10 \\
33 & 5.13 & 4.64 & & +120 \\
34 & 1.17 & 1.86 & 2.59 & +10 \\
43 & 10.5 & 11.6 & - & +49 \\
\hline
\end{tabular}


Table 2. Effect of addition of inorganic phosphate, $\mathrm{Pi}$, to casein dialyzed against $0.5 \%$ $\mathrm{CPBr}$ on activity of liver phosphoprotein phosphatase.

\begin{tabular}{|c|c|}
\hline $\begin{array}{c}\text { Pi added corresponding to } \\
\text { concentration at incubation, } \\
\mu \mathrm{M}\end{array}$ & $\begin{array}{c}\text { Activity in units per } \\
\text { gram of fresh liver }\end{array}$ \\
\hline 0 & 0 \\
100 & 0.1 \\
200 & 0.02 \\
300 & 5.01 \\
400 & 7.74 \\
500 & 9.40 \\
600 & 10.7 \\
\hline
\end{tabular}

enzyme or which exists from the outset, results in a striking inhibition. It is evident that this phosphatase activity can be regulated with great sensitivity by $\mathrm{Pi}$. A further activation through detergents also seems to occur, and the experiments appear to indicate that this effect may consist in a loosening and breaking of covalent phosphorus linkages in the substrate.

The in vitro system applied cannot be considered comparable with the conditions obtaining in vivo, but it is an interesting coincidence that at the maximal activation of the enzyme the concentration of $\mathrm{Pi}$ coincides with the minimal concentration required for oxidative phosphorylation in respiring mitochondria ${ }^{5-7}$. In contradistinction to oxidative phosphorylation and phosphorolysis ${ }^{8}$, where $\mathrm{Pi}$ is included as substrate component, the activating phosphate seems rather to act as a cofactor for the phosphoprotein phosphatase, as is the case in the transformation of serine to glycine ${ }^{9}$. The possibility that $\mathrm{Pi}$ is required to overcome a solubilization effect in the precipitation of calcium phosphate ${ }^{10}$, which is included in the analytic procedure applied, cannot be ruled out, but it seems unlikely, since the phosphate effect exists, even if more faintly, in direct phosphate analysis. On the other hand, it is not inconceivable that through dialysis the substrate loses some phosphate, which is replaced

Table 3. Effect of added $\mathrm{KH}_{\mathbf{2}} \mathrm{PO}_{\mathbf{4}}$ on activity of erythrocyte phosphoprotein phosphatase on phosvitin prepared in water and in $0.01 \mathrm{M}$ cetyltrimetylammonium bromide, CTB.

\begin{tabular}{|c|c|c|c|}
\hline $\begin{array}{c}\text { Added Pi corres- } \\
\text { ponding to final } \\
\text { conc., } \\
\mu \mathrm{M}\end{array}$ & \multicolumn{2}{|c|}{ Activity per $100 \mathrm{mg}$ hemoglobin } & \multirow{2}{*}{$\begin{array}{c}\text { increase } \\
\text { with CTB }\end{array}$} \\
\cline { 2 - 4 } & $\begin{array}{c}1.8 \% \text { phosvitin } \\
\text { in water }\end{array}$ & $\begin{array}{c}2.3 \% \text { phosvitin } \\
\text { in } 0.01 \mathrm{M} \text { CTB }\end{array}$ & \\
\hline 0 & 0 & 0 & 0 \\
150 & 0 & 0.123 & $\infty$ \\
200 & 0.292 & 0.490 & 68 \\
250 & 0.521 & 0.732 & 60 \\
300 & 0.554 & 0.883 & 86 \\
350 & 0.309 & 0.575 & \\
\hline
\end{tabular}

Acta Chem. Scand. 14 (1960) No. 3 
Table 4. Comparison between activities of a hemolysate on phosvitin of different concentrations without and with $0.01 \mathrm{M}$ CTB.

\begin{tabular}{|c|c|c|c|c|c|}
\hline \multirow{2}{*}{$\begin{array}{c}\text { Substrate } \\
\% \\
\text { phosvitin }\end{array}$} & \multicolumn{2}{|c|}{ Substrate in water } & \multicolumn{2}{|c|}{ Substrate in $0.01 \mathrm{M} \mathrm{CTB}$} & \multirow{2}{*}{$\begin{array}{l}\% \text { change of } \\
\text { activity } \\
\text { with CTB }\end{array}$} \\
\hline & $\begin{array}{c}\text { Apparent } \overline{P i} \\
\text { in substrate, } \\
\mu \mathrm{M}\end{array}$ & $\begin{array}{l}\text { Activity } \\
\text { U/100 mg } \\
\text { hemoglobin }\end{array}$ & $\begin{array}{c}\text { Apparent } \mathrm{Pi} \\
\text { in substrate, } \\
\mu \mathrm{M}\end{array}$ & $\begin{array}{c}\text { Activity } \\
\text { U/100 mg } \\
\text { hemoglobin }\end{array}$ & \\
\hline $\begin{array}{c}1 \\
2 \\
3 \\
4 \\
5 \\
\text { hemolysate }\end{array}$ & $\begin{array}{r}7 \\
9 \\
13 \\
14 \\
15 \\
214\end{array}$ & $\begin{array}{l}0.128 \\
0.194 \\
0.199 \\
0.195 \\
0.241\end{array}$ & $\begin{array}{r}15 \\
61 \\
268 \\
470 \\
524\end{array}$ & $\begin{array}{l}0.272 \\
0.334 \\
0.295 \\
0.184 \\
0.178\end{array}$ & $\begin{array}{r}+106 \\
+\quad 72 \\
+\quad 48 \\
-\quad 5 \\
-\quad 26\end{array}$ \\
\hline
\end{tabular}

by added Pi. A simple and rapid exchange between serine-bound phosphorus and $\mathrm{Pi}$ has been shown ${ }^{11}$, and, as has been adduced above, it is conceivable that the dertegence effect is connected with a further loosening of the phosphorus-serine linkage or with activation of the carbinol-group of the serine ${ }^{12}$. In view of the fact that surfactants prove as a rule to be enzyme-inhibitors ${ }^{13}$ it is also more probable that the effect here starts on the substrate; this would entail an intensification of the affinity between enzyme and substrate ${ }^{14}$. The inhibition of excess $\mathrm{Pi}$ may be a competition for the active site of the enzyme.

Acknowledgements. This investigation has been supported by the Swedish Medical Research Council, and by The National Institutes of Health of the United States (Grant H-1142) during studies at the Department of Surgical Research, Medical College of Virginia, Richmond, Va. The author is indebted to Miss Edith Andersson for devoted assistance.

\section{REFERENCES}

1. Norberg, B. Acta Chem. Scand. 4 (1950) 1206.

2. Mecham, D. K. and Olcott, H. S. J. Am. Chem. Soc. 71 (1949) 3670.

3. Singer, M. F. and Fruton, J. S. J. Biol. Chem. 299 (1957) 111.

4. Ernster, L., Zetterström, R. and Lindberg, O. Acta Chem. Scand. 4 (1952) 804.

5. Lardy, H. A. and Wellman, H. J. Biol. Chem. 195 (1952) 215.

6. Gatt, S. and Racker, E. J. Biol. Chem. 234 (1959) 1015, 1024.

7. Wadkins, C. L. and Lehninger, A. L. J. Biol. Chem. 234 (1959) 681.

8. Rowen, J. W. and Kornberg, A. J. Biol. Chem. 193 (1951) 497.

9. Wright, B. E. and Stadtman, T. C. J. Biol. Chem. 219 (1956) 863.

10. Mandl, I., Grauer, A. and Neuberg, C. Biochim. et Biophys. Acta 10 (1953) 540.

11. Ågren, G. Acta Chem. Scand. 13 (1959) 1048.

12. Koshland, D. E. and Erwin, M. Y. J. Am. Chem. Soc. 79 (1957) 2659.

13. Wills, E. D. Biochem. J. 60 (1955) 529.

14. Hughes, D. E. Biochem. J. 45 (1949) 325.

Received November 5, 1959. 